\title{
Intramuscular Diffusion Status of Risperidone and Aripiprazole Long Acting Injectable (LAI) by Ultrasonography
}

\author{
Yuko Yasuhara ${ }^{1}$, Tetsuya Tanioka ${ }^{1}$, Kensaku Takase ${ }^{2}$, Kazushi Motoki ${ }^{3}$, Chie Watari ${ }^{4}$, \\ Koichi Makiguchi', Asumi Atsuta5, Rozzano C. Locsin'1 \\ ${ }^{1}$ Institute of Biomedical Sciences, Graduate School, Tokushima University, Tokushima, Japan \\ ${ }^{2}$ Tokushima Prefectural Central Hospital, Tokushima, Japan \\ ${ }^{3}$ Tokushima Prefectural Kaifu Hospital, Tokushima, Japan \\ ${ }^{4}$ Fujishiro Kensei Hospital, Hirosaki, Japan \\ ${ }^{5}$ Graduate School of Health Sciences, Tokushima University, Tokushima, Japan \\ Email: yasuhara@medsci.tokushima-u.ac.jp
}

Received 15 February 2016; accepted 28 March 2016; published 31 March 2016

Copyright (C) 2016 by authors and Scientific Research Publishing Inc.

This work is licensed under the Creative Commons Attribution International License (CC BY). http://creativecommons.org/licenses/by/4.0/

(c) (i) Open Access

\section{Abstract}

The aim of this study was to consider the characteristics of intramuscular diffusion status of risperidone and aripiprazole long acting injectable (LAI) by ultrasonography. Subjects were 40 adult subjects diagnosed with schizophrenia and treated with LAI [32 patients were risperidone LAI (RLAI) and 8 patients were aripiprazole LAI (ALAI)]. However, in this paper, only three cases (one RLAI case and 2 ALAI cases) were selected to illustrate the diffusion effects of both LAI. Dorsogluteal intramuscular (IM) injection sites were measured at prone position using the "double cross" method. Before LAI injection, the distance from the epidermis to the under-fascia (DEUF), and distance from the epidermis to the iliac bone (DEI) at the IM injection site were assessed by using ultrasonography: 1) the injection needle was inserted to the gluteus medius, and 2) observed the diffusion status within the muscle injected RLAI and ALAI were confirmed using the B-mode ultrasonography. Both RLAI and ALAI were depicted as high echogenicity with acoustic shadowing. It was considered that the diffusion states of LAIs by ultrasonography were important time course evaluations providing objective evidence.

\section{Keywords}

Diffusion Status, Risperidone, Aripiprazole, Long Acting Injectable (LAI), Ultrasonography 


\section{Introduction}

Long-acting injectable (LAI) is an approach to administering typical and atypical anti-psychotic medications for patients with schizophrenia [1]. Since the introduction of risperidone LAI (RLAI) in 2009 in Japan [2], two additional atypical antipsychotics have become available in LAI formulation: paliperidone [3] (2013) and aripiprazole [4] (2015).

RLAI is the first atypical antipsychotic available in an injectable formulation, and its efficacy and tolerability have been demonstrated in clinical trials [5]-[7]. Recently, a second generation antipsychotic is developed as a long-acting injection, in the form of a suspension of lyophilized aripiprazole reconstituted with an aqueous diluent, for intramuscular administration [8]. Aripiprazole LAI (ALAI), an extended-release injectable suspension for intramuscular use, is the first dopamine partial agonist available as an LAI and is approved for the treatment of schizophrenia [9] [10]. ALAI has a lower metabolic risk [11] and a lower risk for QT prolongation [12]. Although these different depot options help with medication adherence and encourage better treatment outcomes, these options differ in terms of specific indications, approved injection sites, needle gauge and length, injection interval, availability of prefilled syringes, and potential for drug-drug interactions [13].

In many countries, these LAIs are approved for the treatment of schizophrenia and administered intramuscularly using the deltoid or gluteal muscles [14]. The suggested site for RLAI is the gluteal muscle with a needle length of 2 inches $(50 \mathrm{~mm})$ [15], while with ALAI [16] the suggested site is the gluteal muscle with a needle length of 1.5 inches (38 mm) [17].

LAIs are administered using different types of needle gauges and for intramuscular (IM) injection. Nurses and physicians need to assess the injection sites and how to insert the needles. Previous study [18] reports injection needle lengths for optimal IM injection for adult subjects. Previous research using ultrasonographic data is used to detect insertion sites [19], depth of needle insertion into specific muscles [20], and visualization of medication dispersions [21].

Some disadvantages of LAIs include: retention of medications in the muscles for a long period of time. It is also known that IM injections have injection site side-effects [22]. To prevent these, it is critical to evaluate the anatomical and morphological changes before and after LAIs are injected by using a non-invasive ultrasonography. However, little is known about how LAIs are diffused in the gluteal muscle tissue.

The aim of this study is to consider the characteristics of intramuscular diffusion status of RLAI and ALAI by the ultrasonography.

\section{Materials and Methods}

\subsection{Subjects}

Subjects were 40 adult subjects diagnosed with schizophrenia and treated with LAI (32 RLAI and 8 ALAI). These patients were recruited from hospitals within the Kumamoto and Aomori prefectures in Japan. Criteria for participant selection included, being diagnosed with schizophrenia based on the International Statistical Classification of Diseases and Related Health Problems, Tenth Revision (ICD-10) F2 criteria. Inclusion criteria were a diagnosis of schizophrenia; treated with RLAI or ALAI; and aged between 20 - 70 years. Exclusion criteria were diagnosis of systemic or neurologic diseases, including disturbances of hematopoiesis; pregnant; dependent on any substances other than nicotine during the 5 years before enrollment; and communication difficulty.

\subsection{Methods of Collection of Typical Examples, and the Study Period}

The study was conducted from June 2013 to November 2015. During this period, all subjects were examined by ultrasonography. However, in this paper, only three cases (one RLAI and 2 ALAI cases) were selected to illustrate the diffusion effects of both LAI.

\subsection{Measurement}

Dorsogluteal IM injection sites were measured with the subjects at prone position to identify the injection site using the "Double Cross" method [23]. This method divides the buttocks with an imaginary cross then dividing the upper outer quadrant again by another imaginary cross.

Before LAI injection, the distance from the epidermis to the under-fascia (DEUF), and distance from the epi- 
dermis to the iliac bone (DEI) at IM injection site was assessed using ultrasonography. Then, 1) the injection needle was inserted to the gluteus medius, and 2) observation of the diffusion state of injection solution under the B-mode ultrasonography. All ultrasonographic measurements were performed by an experienced sonographer using a 7.5 MHz linear and convex array transducer and the Digital Diagnostic Ultrasound Scanner (Hitachi Medical Corporation, Japan).

\subsection{Ethical Consideration}

This study was conducted after approval was received from Tokushima University Hospital Ethics Committee (approval number 2948). Both verbal and written consents were obtained from the prospective subjects of the study. Patient consent for ultrasonography images was also obtained. The consent also included a statement of understanding that images may be used for educational purposes, lectures, and publications.

\section{Results}

Figures 1-3 exhibit the diffusion of RLAI and ALAI in the corresponding muscles of each case. In all subjects, injected LAIs in the muscle were clearly confirmed on B-mode images. Both RLAI and ALAI in all of the 40 cases showed the high echogenicity with acoustic shadowing. Immediately after the injection of RLAI and ALAI into the muscles the medications could be monitored by ultrasonography in all cases. However, the degree of acoustic shadowing of ALAI was stronger than RLAI.

Case 1: Typical Example of RLAI Ultrasound Data

Figure 1 is a typical example of RLAI. Gender: male. Age: 50 years old. Height: $158.0 \mathrm{~cm}$. Weight: $45.0 \mathrm{~kg}$. BMI: $18.1 \mathrm{~kg} / \mathrm{m}^{2}$. Left side DEUF of gluteus medius was $9.4 \mathrm{~mm}$, and DEI was $50.1 \mathrm{~mm}$.

\section{Case 2: Typical Example of ALAI Ultrasound Data}

Figure 2 is atypical example of the diffusion of the ALAI. Gender: male. Age: 57 years old. Height: $148 \mathrm{~cm}$. Weight: $61.5 \mathrm{~kg}$. BMI: $28.08 \mathrm{~kg} / \mathrm{m}^{2}$. ALAI dosage: $400 \mathrm{mg}$. Right side DEUF of gluteus maximus was $16.2 \mathrm{~mm}$, gluteus medius was $21.4 \mathrm{~mm}$, and DEI was $63.4 \mathrm{~mm}$.
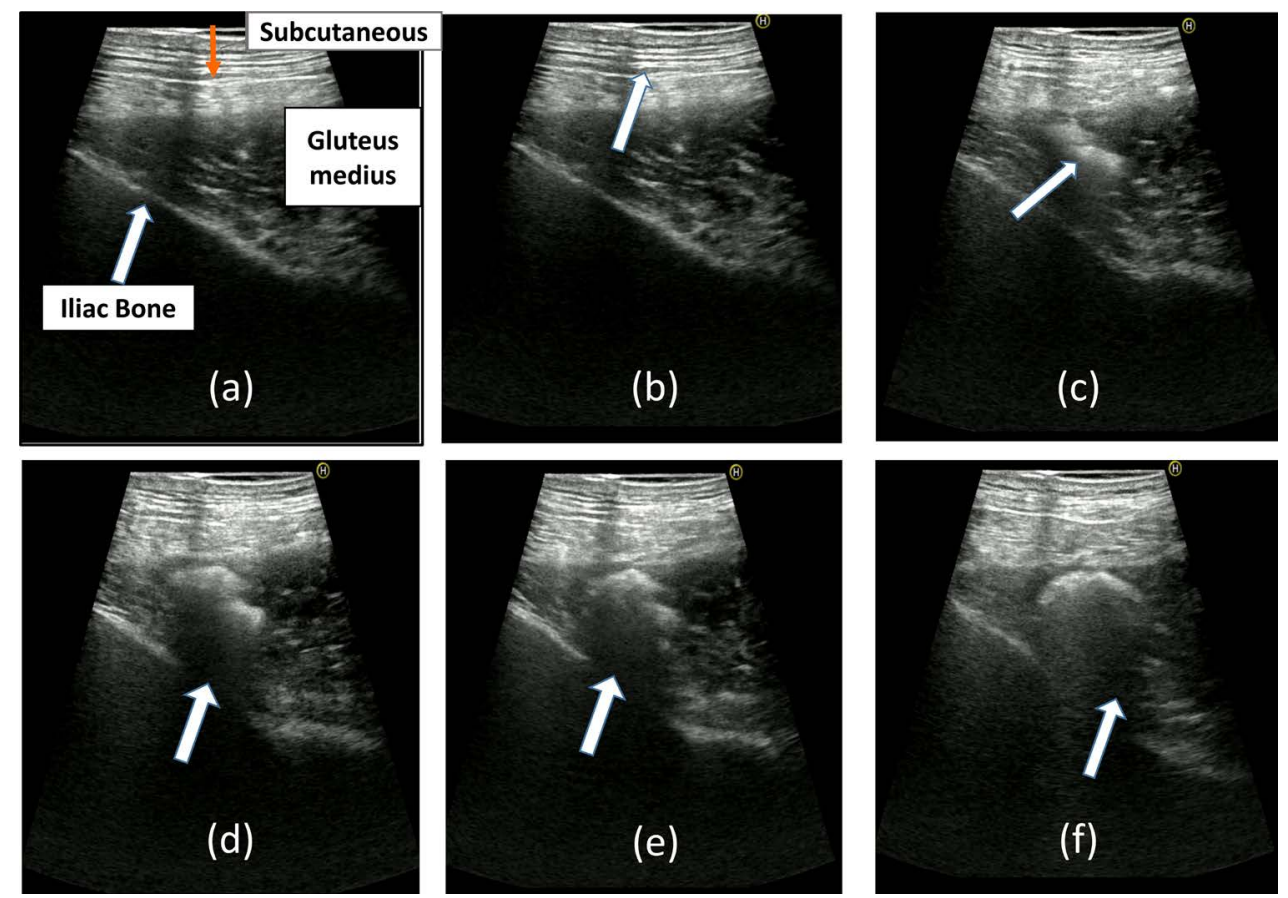

Figure 1. Typical example of ultrasound images in RLAI (case 1) from before injection to after injection. (a) Iliac bone appears as a distinct bright echogenic line with no visible structures beneath. (b) View of gluteal muscle and fascia using a convex transducer. (c) This is the image of RLAI at the time of start injection. (d) This was the image in RLAI diffusion. In the deep area, attenuation by acoustic shadow was observed by RLAI injection, a state where the iliac became unclear. (e) This situation was internal flow of RLAI in the muscle. (f) This is an image after RLAI injection. 

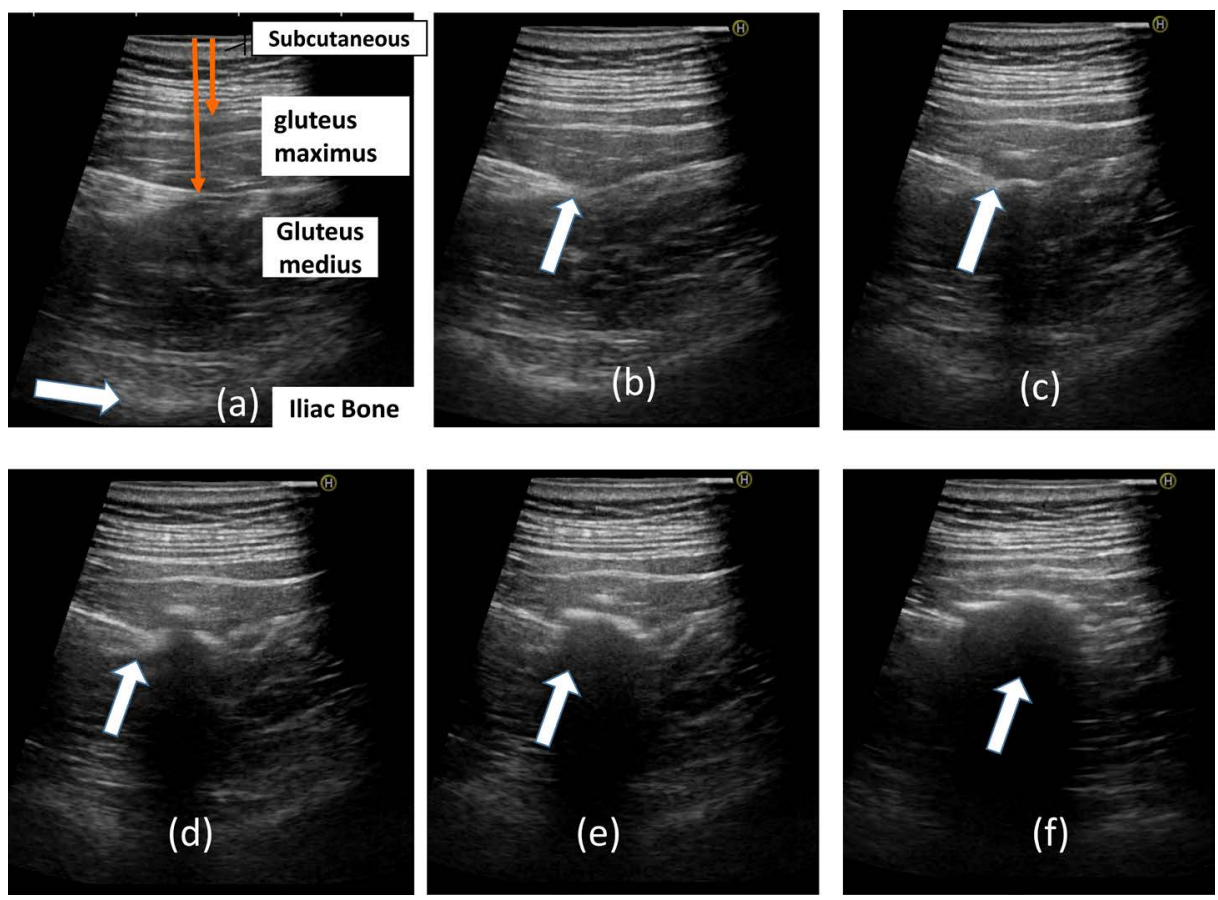

Figure 2. A patient with schizophrenia, Gender: man, Aged: 57 . Height: $148 \mathrm{~cm}$. Weight: $61.5 \mathrm{~kg}$. BMI: $28.08 \mathrm{~kg} / \mathrm{m}^{2}$. ALAI dosage: $400 \mathrm{mg}$. Right side DEUF of gluteus maximus was $16.2 \mathrm{~mm}$ and gluteus medius was $21.4 \mathrm{~mm}$ Left side DEI was $63.4 \mathrm{~mm}$. (a) Iliac Bone appears as a distinct bright echogenic line with no visible structures beneath. (b) View of gluteal muscle: By the insertion of the needle to the gluteus medius muscle membrane, distortion of the fascia is observed. (c) this is the image of RLAI at the time of start injection. (d) In the deep area, attenuation by acoustic shadow is observed by ALAI injection. This image is an injection of ALAI into the gluteus medius; diffusion of ALAI is also observed in the gluteus maximus muscle. (e) Acoustic shadow is maximized by the injection of ALAI, the iliac cannot verify in this image. (f) This is an image after ALAI injection.

\section{Case 3: Typical Example of ALAI Ultrasound Data}

Figure 3 is a typical example of the diffusion of the ALAI. Gender: female. Age: 56 years old. Height: 148 cm. Weight: $63.9 \mathrm{~kg}$. BMI: $29.17 \mathrm{~kg} / \mathrm{m}^{2}$. ALAI dosage: $400 \mathrm{mg}$. Left side DEUF of gluteus medius was 17.4 $\mathrm{mm}$, and DEI was $54.0 \mathrm{~mm}$.

\section{Discussion}

The LAIs were noted as high echogenic masses with an acoustic shadowing. Also, B-mode finding can provide the minute information of the locations, sizes, shapes of injected LAIs.

Acoustic shadowing is an artifact seen in ultrasound imaging in which an intensely echogenic line appears at the surface of structures which block the passage of sound waves [24]. In RLAI, part of the ilium was not visualized by an acoustic shadow from midway through injection. However, the attenuation by the acoustic shadow in the deep part near the center of the tip around the injection needle immediately after ALAI was injected. Therefore, the ilium was not visualized.

It was confirmed that the difference between the diffusion images of the drug particles after dissolution of RLAI and ALAI was evident. The particle size of the microsphere of RLAI formulation has been reported to be between 25 and 150 micrometers [6]. It might be the differences of the composition of the suspension that contributed to the cause of the difference of the acoustic shadow on post-injection. Also, RLAI has attached microspheres with the drug, and is uneven in the shape of the surface. The reports from clinical site, the aqueous solution after dissolution indicates that there is a clotting potential of microsphere by its dosage form in an injection syringe.

On the one hand, ALAI is a lyophilized powder that needs to be reconstituted with sterile water to form an injectable suspension without affecting the original molecule. Aripiprazole having a mean particle size of about 1 to 10 microns [10] as described above is characterized by particles which are smaller than risperidone. 

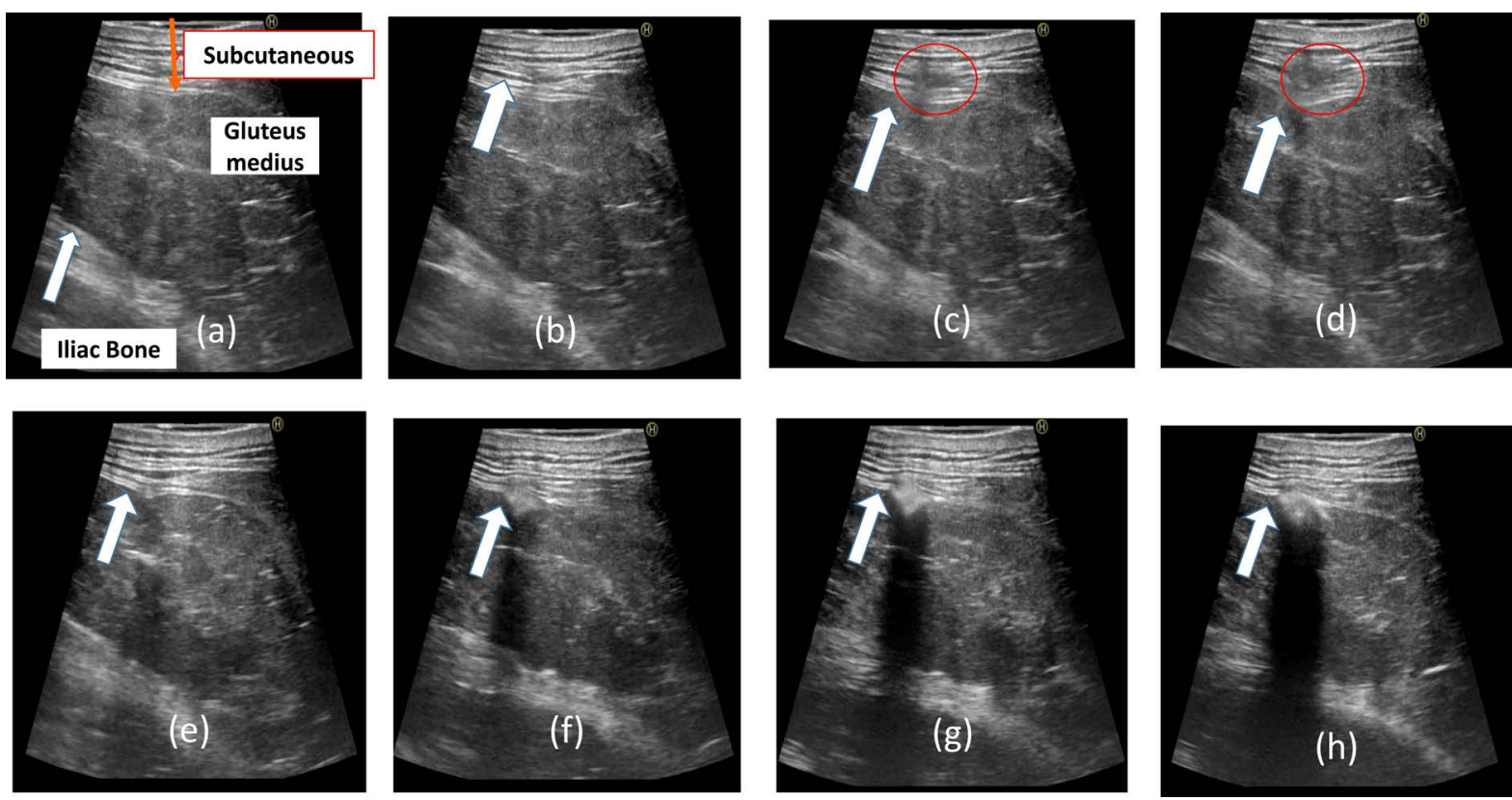

Figure 3. A patient with schizophrenia, Gender: woman. Aged: 56 . Height: $148 \mathrm{~cm}$. Weight: $63.9 \mathrm{~kg}$. BMI: $29.17 \mathrm{~kg} / \mathrm{m}^{2}$. ALAI dosage: $400 \mathrm{mg}$. Left side DEUF of gluteus medius was $17.4 \mathrm{~mm}$ Left side DEI was $54.0 \mathrm{~mm}$. (a) Before needle puncture, iliac can be confirmed. (b) Insertion position of the injection needle. (c) The tip of the needle has been confirmed in the gluteus maximus. (d) The needle has been confirmed in the gluteus maximus muscle, the fascia of the gluteus maximus is distorted at the bottom by pressure on the fascia of the injection needle. (e) By the penetration of the injection needle, the gluteus maximus is returned to the original position. (f) ALAI injection at the start of the image. By injection of ALAI, attenuation by acoustic shadow was observed in the deep part. (g) By acoustic shadow due to the injection of ALAI, iliac is unclear.

The B-mode images of ALAI had more sharpened margins and strong acoustic shadowing compared with those of RLAI. This study provided a non-invasive method for distinguishing these LAIs.

The RLAI is administered to the buttocks using a dedicated injection needle size (20 G, 2 inches). Also, ALAI is administered using the $22 \mathrm{G}(38 \mathrm{~mm})$ injection needle in Japan. Comparison of the injection needle, ALAI has a small inner diameter of the needle than the RLAI. Therefore, there is a possibility that ALAI injection can be administered faster than RLAI. Internal diameter is proportional to the outside diameter, resulting in difference in time of delivery of medication during injection of the drug solution with RLAI and ALAI. There is a possibility of an image difference considering diffusion state.

Many LAIs are formulated to create a poorly soluble depot from which the active agent is delivered over time. In animal experiments (in both non-human primates and rodents) [25], after LAI injected into intramuscular and subcutaneous tissue was reported to have reaction changes. Therefore, it was thought that these long acting injectables are at risk for developing localized chronic-active inflammation in the tissue.

In human being, RLAI studies [26] [27] reported that drug injection sites for the majority of patients revealed no redness, swelling, tenderness, or induration at either the deltoid muscle or gluteal muscle injection sites. Moreover, for the majority of patients, ALAI study [28] reported absence of any pain, redness, swelling and induration following the first and last injections of aripiprazole $400 \mathrm{mg}$ monthly.

Nevertheless, severe complications from injection site reactions have been reported [29]. Clinically, it is difficult to evaluate and study the precise location of an injected medication into the buttocks. Computed Tomography (CT), can evaluate whether the drug reached the muscle or the subcutaneous tissue [30] [31]. In the clinical practice, CT is difficult to use to evaluate the precise location of an injected medication into the buttocks. Therefore, it is not a standard procedure to use any other monitoring device during hypodermic injections.

An actual visualization method of the site of injection immediately after injection is required to accurately assess the deposition of the medication during IM injections. It was considered a beneficial finding from using the ultrasonographic evaluation to determine the diffusion status of medications injected into the muscle, in patients treated with LAI. Therefore it is important as the future of clinical studies, to clarify the diffusion of LAI in the muscle using the B-mode ultrasonography. 
In this paper, we reported the characteristics of the diffusion status of RLAI and ALAI. It was considered that the diffusion state was related to the dose and muscle mass and type of drugs, and the difference in the rate of administration. However, the data exhibited that the extensive shadowing may severely diminish image quality or completely erase the information behind the injected LAIs. This was one of the disadvantages in evaluating the IM injection by ultrasonography.

It is important to note, however, that the procedure for data collection was used in four other successful investigations by Tanioka, Yasuhara, and Sakamaki et al. [19]-[21] [32]. This procedure provided credible data on diffusion location, rates, and absorption using RLAI. While prior studies used risperidone, the present study used ultrasound imaging of aripiprazole. However, one of the major limitations of this study is concerning subject selection. While RLAI was administered twice a month, ALAI was administered to patients only once a month. In particular, ALAI was only launched in 2015 in Japan. Therefore, prospective subjects were limited and difficult to recruit to obtain comparable subjects. Nevertheless, the protocol of the data collection was not a problem. Similarly, the ultrasonographic instrument was always available at the appointed time for data collection.

\section{Conclusion}

This study of the diffusion status and differences in the muscle of RLAI and ALAI was able to confirm the effect of using different needle sizes through diffusion rates shown by the B-mode ultrasonography. Both RLAI and ALAI medications were depicted as a high echogenic mass with acoustic shadowing. B-mode ultrasonography was one of the most useful monitoring tools for obtaining data from patients with schizophrenia who were treated with LAIs. It was considered that B-mode ultrasonography could provide objective evidence in time course evaluations.

\section{Acknowledgements}

The authors would like to thank the subject patients of the study and all staff members of the hospital who have helped in this research study.

\section{References}

[1] Kane, J.M. and Garcia-Ribera, C. (2009) Clinical Guideline Recommendations for Antipsychotic Long-Acting Injections. The British Journal of Psychiatry, 195, S63-S67. http://dx.doi.org/10.1192/bjp.195.52.s63

[2] Janssen Pharmaceutical K.K. (2009) New Release RISPERDAL Consta ${ }^{\circledR}$ Intramuscular Injection. (In Japanese) http://www.janssen.com/japan/press-release/20060623

[3] Janssen Pharmaceutical K.K. (2013) New Release XEPLION ${ }^{\circledR}$ Aqueous Suspension for IM Injection. (In Japanese) http://www.janssen.com/japan/press-release/20130920

[4] Otsuka Pharmaceutical Co. (2015) Otsuka Granted Approval in Japan for a New Formulation of ABIILIFYABILIFY for Extended-Release Injectable Suspension, for Intramuscular Use-Indicated for Schizophrenia. https://www.otsuka.co.jp/en/company/release/2015/0326_03.html

[5] Covell, N.H., McEvoy, J.P., Schooler, N.R., Stroup, T.S., Jackson, C.T., Rojas, I.A., Essock, S.M. and Schizophrenia Trials Network (2012) Effectiveness of Switching from Long-Acting Injectable Fluphenazine or Haloperidol Decanoate to Long-Acting Injectable Risperidone Microspheres. The Journal of Clinical Psychiatry, 73, 669-675. http://dx.doi.org/10.4088/JCP.11m07074

[6] D'Souza, S., Faraj, J.A., Giovagnoli, S. and Deluca, P.P. (2014) Development of Risperidone PLGA Microspheres. Journal of Drug Delivery, 2014, Article ID: 620464. http://dx.doi.org/10.1155/2014/620464

[7] Williams, R., Chandrasena, R., Beauclair, L., Luong, D. and Lam, A. (2014) Risperidone Long-Acting Injection in the Treatment of Schizophrenia: 24-Month Results from the Electronic Schizophrenia Treatment Adherence Registry in Canada. Neuropsychiatric Disease and Treatment, 2014, 417-425.

[8] Chue, P. and Chue, J. (2015) A Review of Aripiprazole Long-Acting Injection. Current Medical Research and Opinion, 32, 441-452.

[9] Kane, J.M., Peters-Strickland, T., Baker, R.A., Hertel, P., Eramo, A., Jin, N., Perry, P.P., Gara, M., McQuade, R.D., Carson, W.H. and Sanchez, R. (2014) Aripiprazole Once-Monthly in the Acute Treatment of Schizophrenia: Findings from a 12-Week, Randomized, Double-Blind, Placebo-Controlled Study. The Journal of Clinical Psychiatry, 75, 12541260. http://dx.doi.org/10.4088/JCP.14m09168 
[10] Kostanski, J.W., Matsuda, T., Nerurkar, M. and Naringrekar, V.H. (2007) Controlled Release Sterile Injectable Aripiprazole Formulation and Method. US Patent No.8030313 B2.

[11] Kane, J.M., Sanchez, R., Baker, R.A., Eramo, A., Peters-Strickland, T., Perry, P.P., Johnson, B.R., Tsai, L.F., Carson, W.H., McQuade, R.D. and Fleischhacker, W.W. (2015) Patient-Centered Outcomes with Aripiprazole Once-Monthly for Maintenance Treatment in Patients with Schizophrenia: Results from Two Multicenter, Randomized, Double-Blind Studies. Clinical Schizophrenia \& Related Psychoses, 9, 79-87. http://dx.doi.org/10.3371/CSRP.KASA.022015

[12] Leonard, C.E., Freeman, C.P., Newcomb, C.W., Bilker, W.B., Kimmel, S.E., Strom, B.L. and Hennessy, S. (2013) Antipsychotics and the Risks of Sudden Cardiac Death and All-Cause Death: Cohort Studies in Medicaid and Dually-Eligible Medicaid-Medicare Beneficiaries of Five States. Journal of Clinical and Experimental Cardiology, 10, 1-9.

[13] Citrome, L. (2013) New Second-Generation Long-Acting Injectable Antipsychotics for the Treatment of Schizophrenia. Expert Review of Neurotherapeutics, 13, 767-783. http://dx.doi.org/10.1586/14737175.2013.811984

[14] Fleischhacker, W.W. (2009) Second-Generation Antipsychotic Long-Acting Injections: Systematic Review. The British Journal of Psychiatry, 195, S29-S36. http://dx.doi.org/10.1192/bjp.195.52.s29

[15] Janssen Pharmaceutical K.K. (2015) Risperdal CONSTA ${ }^{\circledR}$ Intramuscular injection, Interview Form. (In Japanese) http://www.janssenpro.jp/cs/Satellite?pagename=jpro/BlobDspBody\&c=simage\&cid=1402062276447

[16] Otsuka Pharmaceutical Co. (2015) ABILIFY ${ }_{\circledast}$ Prolonged Release Aqueous Suspension for IM Injection. (In Japanese) http://database.japic.or.jp/pdf/newPINS/00065429.pdf

[17] Otsuka Pharmaceutical Co. (2015) ABILIFY ${ }_{\circledast}$ Prolonged Release Aqueous Suspension for IM Injection, Interview Form. (In Japanese) https://www.otsuka-elibrary.jp/di/prod/product/file/abj/abj_if.pdf

[18] Takahashi, Y., Kikuchi, K., Miura, N. and Ishida, Y. (2014) Appropriate Needle Insertion Depth for Intramuscular Injection Based on Assessment of BMI. Journal of Japan Academy of Nursing Science, 34, 36-45. (In Japanese) http://dx.doi.org/10.5630/jans.34.36

[19] Yasuhara, Y., Hirai, E., Sakamaki, S., Tanioka, T. and Motoki, K. (2012) Using Ultrasonography in Evaluating the Intramuscular Injection Techniques Used for Administering Drug Treatment to Schizophrenic Patients in Japan. The Journal of Medical Investigation, 59, 213-219. http://dx.doi.org/10.2152/jmi.59.213

[20] Tanioka, T., Sakamaki, S., Yasuhara, Y., Tomotake, M., Takase, K., Watari, C., Makiguchi, K., Locsin, R., Motoki, K. and Inui, T. (2013) Optimal Needle Insertion Length for Intramuscular Injection of Risperidone Long-Acting Injectable (RLAI). Health, 5, 1939-1945. http://dx.doi.org/10.4236/health.2013.512262

[21] Yasuhara, Y., Skamaki, S., Tanioka, T., Motoki, K., Sasakawa, C., Takase, K. and Kawanishi, C. (2013) Optimal Length of Intramuscular Injection Needle and Drug Absorption by Ultrasound Evaluation. Neurosonology, 25, 91-94. (In Japanese) http://dx.doi.org/10.2301/neurosonology.25.91

[22] Beyea, S.C. and Nicoll, L.H. (1995) Administration of Medications via the Intramuscular Route: An Integrative Review of the Literature and Research-Based Protocol for the Procedure. Applied Nursing Research, 8, 23-33. http://dx.doi.org/10.1016/S0897-1897(95)80279-7

[23] Cocoman, A. and Murray, J. (2008) Intramuscular Injections: A Review of Best Practice for Mental Health Nurses. Journal of Psychiatric and Mental Health Nursing, 15, 424-434. http://dx.doi.org/10.1111/j.1365-2850.2007.01236.x

[24] Radiopaedia.org (2009) About Acoustic Shadowing. http://radiopaedia.org/articles/acoustic-shadowing

[25] Paquette, S.M., Dawit, H., Hickey, M.B., Merisko-Liversidge, E., Almarsson, Ö. and Deaver, D.R. (2014) Long-Acting Atypical Antipsychotics: Characterization of the Local Tissue Response. Pharmaceutical Research, 31, 2065-2077. http://dx.doi.org/10.1007/s11095-014-1308-4

[26] Kane, J.M., Eerdekens, M., Lindenmayer, J.P., Keith, S.J., Lesem, M. and Karcher, K. (2003) Long-Acting Injectable Risperidone: Efficacy and Safety of the First Long-Acting Atypical Antipsychotic. The American Journal of Psychiatry, 160, 1125-1132. http://dx.doi.org/10.1176/appi.ajp.160.6.1125

[27] Quiroz, J.A., Rusch, S., Thyssen, A. and Palumbo, J.M. (2011) Deltoid Injections of Risperidone Long-Acting Injectable in Patients with Schizophrenia Stuart Kushner. Innovations in Clinical Neuroscience, 8, 20-28.

[28] Fleischhacker, W.W., Sanchez, R., Perry, P.P., Jin, N., Peters-Strickland, T., Johnson, B.R., Baker, R.A., Eramo, A., McQuade, R.D., Carson, W.H., Walling, D. and Kane, J.M. (2014) Aripiprazole Once-Monthly for Treatment of Schizophrenia: Double-Blind, Randomised, Non-Inferiority Study. The British Journal of Psychiatry, 205, 135-144. http://dx.doi.org/10.1192/bjp.bp.113.134213

[29] Leung, J.G., Kooda, K.J., Frazee, E.N., Nelson, S. and Moore, K.M. (2015) Paliperidone Palmitate Associated with Necrotizing Deep Tissue Infection and Sepsis Requiring Surgical Intervention. Case Reports in Psychiatry, 2015, Article ID: 364325. http://dx.doi.org/10.1155/2015/364325

[30] Dayananda, L., Belaval, V.V., Raina, A. and Chandana, R. (2014) Intended Intramuscular Gluteal Injections: Are They Truly Intramuscular? Journal of Postgraduate Medicine, 60, 175-178. http://dx.doi.org/10.4103/0022-3859.132334 
[31] Chan, V.O., Colville, J., Persaud, T., Buckley, O., Hamilton, S. and Torreggiani, W.C. (2006) Intramuscular Injections into the Buttocks: Are They Truly Intramuscular? European Journal of Radiology, 58, 480-484. http://dx.doi.org/10.1016/j.ejrad.2006.01.008

[32] Sakamaki, S., Zhao, Y., Yasuhara, Y., Motoki, K., Takase, K., Abe, H., Miyazaki, K., and Tanioka, T. (2014) Consideration of Long Acting Injection Procedure into the Gluteal Medius Muscle by Real-Time B-Mode Ultrasonography: Case Reports of Patients Who Observed Injection Site Reactions or Blood Back-Flow. Japanese Journal of Clinical Psychopharmacology, 17, 927-937. (In Japanese) 